\title{
Cultural support workers in the Aotearoa New Zealand healthcare setting: Challenge and opportunity for health social work
}

\author{
Maree Goh, Mercy Hospice, Auckland, New Zealand
}

\begin{abstract}
INTRODUCTION: In Aotearoa New Zealand, as elsewhere in the world, healthcare providers are seeking better ways to engage with increasingly ethnically and linguistically diverse communities. The use of cultural support workers (CSWs) to act as a bridge between services and such communities is proving to be an effective strategy for achieving this. For the social work profession, the advent of CSW roles presents both challenges and opportunities.
\end{abstract}

APPROACH: A review of literature outlines the challenge of delivering culturally responsive and appropriate services to migrant and refugee communities and describes the role played by CSWs to increase the cultural understanding of healthcare providers and improve health outcomes for these communities. The impact of such roles on health social work is explored and how current social work education prepares practitioners for practice in an increasingly multicultural society.

CONCLUSIONS: This article outlines the key issues that arise from the introduction of CSWs, the potential for collaboration and the opportunity that exists for health social work to refocus and redefine its role in the healthcare setting.

KEYWORDS: Cultural support; healthcare services; social work; health disparities

AOTEAROA NEW ZEALAND SOCIAL WORK 31(4), 48-59.

CORRESPONDENCE TO: Maree Goh

mgoh@mh.org.nz
This article begins by outlining the demographic changes that have occurred in Aotearoa New Zealand in recent times; the barriers faced by new migrants and refugees in accessing culturally appropriate healthcare services; some of the local initiatives developed to address these barriers; and the role of the cultural competence in healthcare. It will describe the introduction of CSWs, with reference to local and international literature, their role in supporting migrant communities and will explore the implications for social work practitioners-both the challenges and the opportunities this presents for health social work practice here in Aotearoa New Zealand.
The impact of globalisation and migration means that healthcare providers are now required to meet the needs of increasingly ethnically and linguistically diverse communities. As healthcare providers also become more ethnically and linguistically diverse, healthcare interactions require a greater level of skill and cultural understanding (Cawley, Marshall, Lo, \& Koenig, 2002; Kagawa-Singer \& Blankhall, 2001; Nguyen, Ho, \& Williams, 2011).

Healthcare providers, both overseas and here in Aotearoa New Zealand, are addressing this challenge by using a range of different strategies to deliver services that are culturally appropriate, accessible 
and sustainable (Henderson \& Kendall, 2011; Mortensen, Latimer, \& Yusuf, 2014). These strategies include: community health education programmes; the development of culturally specific resources (booklets, videos, online programmes); and the use of cultural liaison or cultural support workers (CSWs).

In the Auckland region, the most ethnically diverse in the country (Walker, 2014), the use of CSWs is seen as a strategy to improve access to services and improve health outcomes for culturally and linguistically diverse (CALD) communities. CALD is the term used to describe culturally and linguistically diverse populations from Asian, Middle Eastern, Latin American and African backgrounds which have made Aotearoa New Zealand their home in recent years (Mortensen et al., 2014; Walker, 2014). The CSW role is seen as effective in creating a "bridge" with such communities, improving access to services by identifying the barriers, and helping to design and develop services that are more responsive to the needs of their communities (Mortensen et al., 2014).

While the introduction of CSWs into the healthcare setting improves the delivery of culturally responsive healthcare (Henderson \& Kendall, 2011; Mortensen et al., 2014; Perese, Ulugia-Veukiso, Samu, Sepuloni, \& Peteru, 2009; Spencer, Gunter, \& Palmisiano, 2010) their presence also has an impact on social work practice in the healthcare setting. With CSWs undertaking many of the traditional tasks of social workers, including advocacy, information-giving and the provision of emotional support, the professional identity of social work faces a significant challenge. Describing the various tasks undertaken by CSWs, Darnell argues that their duties "are consistent with two core social work functions: (1) helping people obtain services and (2) helping communities or groups provide or improve services" (2007, p. 82).

While social work practitioners are committed to ideals of equality of access and inclusiveness, the use of CSWs presents challenges to the role and contribution of social work in the healthcare setting. It also presents a challenge to social work educators to reflect on the current education and curriculum and how well it equips practitioners to work effectively with the multicultural setting that is Aotearoa New Zealand. This will be explored further later in the article.

This challenge, however, also provides great opportunities for the social work profession. The opportunity to collaborate with CSWs and work alongside them to improve the cultural understanding and knowledge of practitioners and also the opportunity to advocate for CSWs to be recognised as integral and valuable members of the healthcare team (Goh, 2018).

Social work practitioners in the healthcare setting have faced many challenges over the decades (Beddoe \& Deeney, 2012; Giles, Gould, Hart, \& Swancott, 2007; Schofield, 2001) and so, again, must consider how the profession responds to this challenge, while recognising the new scope and opportunities that exist for practice as the populations served change (Craig \& Muskat, 2013; Giles, 2009).

This aim of this article is to provide an overview of this new challenge. It will begin by describing the cultural landscape of Aotearoa, the health services for migrant communities, the challenges and the initiatives that have responded to these challenges. It will explore the role of SW professional bodies in providing leadership and guidance regarding cultural competence, and then focus on the role of CSWs and their relationship with social work.

\section{Refugee and migrant communities in Auckland}

Changes to Aotearoa New Zealand's immigration laws over the past two decades have seen dramatic demographic 
changes with our largest city, Auckland, now described as superdiverse. The term superdiversity is a relatively recent way to define demographic diversity; it is used by academics to define cities and countries where more than $25 \%$ of the resident population is made up of migrants or where more than 100 nationalities are represented (Chen, 2015). In Auckland, where there are over 200 ethnicities and more than 160 languages being spoken, superdiversity is the new reality (Chen, 2015; Walker, 2014).

Auckland has always been considered a cosmopolitan city but, in the 1990s, a relaxation of the immigration rules saw large numbers of migrants make Auckland home (Mortensen, 2011). The biggest increase in numbers has been in those from Asia. This includes migrants from Hong Kong, Malaysia, Taiwan, the Philippines and Mainland China. Auckland is home to two-thirds of the Aotearoa New Zealand Asian population, and half of the Middle Eastern, Latin American and African (MELAA) populations. It is estimated that over one-third of Aucklanders were born overseas (Walker, 2014).

In the 2013 census, almost $50 \%$ of Auckland's population identified as either Māori, Asian or Pacific peoples, with over one-third, $40 \%$ of the population, not born in Aotearoa New Zealand. The biggest change from the previous census in 2006 was in the growth of those identifying as Asian from $17.2 \%$ in 2006 to $20.9 \%$ in 2013. The ethnic composition of the population is projected to continue to change over time, with growth expected in the proportion of Asian peoples in the population and a reduction in the proportion of European peoples (Walker, 2014).

While many of the new arrivals to Auckland are migrants, there are also many refugees who settle in the Auckland area (Mortensen, 2011; Walker, 2014). Currently, Aotearoa New Zealand accepts approximately 1,500 refugees each year from countries including Afghanistan, Algeria, Burma, Bhutan, Burundi, Bosnia, Colombia Eritrea, Ethiopia, Iran, Iraq, Kosovo, Palestine, Rwanda, Sierra Leone, Sri Lanka, Somalia, the Democratic Republic of Congo, Sudan and Zimbabwe. For the 10-year period, 2009-2010 to 2018-2019, the top five nationalities of those accepted under the Refugee Quota Arrivals were from Myanmar, Syria, Columbia, Bhutan and Afghanistan. It is estimated that approximately $60 \%$ of those will reside in the Auckland region (Immigration New Zealand, 2019).

\section{Access to health care}

While refugees are granted the rights of Aotearoa New Zealand residency on arrival, this entitlement does not guarantee them easy access to culturally sensitive and appropriate healthcare services, which can be "limited and inequitable" (Mortensen, 2011, p. 123). Access to culturally appropriate and responsive healthcare services is recognised as an issue for both refugee and migrant communities with access hindered by a variety of factors. Lawrence and Kearns (2005) and Nguyen et al. (2011) describe some of these factors, which include:

- The stress and anxiety associated with resettlement in a new country with very little or no support. The impact of wider determinants on health, such as immigration requirements, employment and housing, plays a large role in access to appropriate services.

- Differing understandings of illnesses and healthcare systems-for example, unfamiliarity with the requirement to make an appointment to see a general practitioner, the process of referrals and waiting lists.

- Trust, particularly for those who have come from areas of conflict. This is also a potential concern when interpreters are required, as communities are 
often small and there is fear that very personal information will be passed on.

- Communication difficulties-in both verbal consultations and in written information. (Nguyen et al., 2011). For example, communications from hospitals, appointments and prescription instructions may all present challenges.

- Cost of accessing services, including time off work, doctor visits and prescriptions, is a significant issue for those living on a very limited income.

Physical barriers, such as no access to transport, unfamiliarity with public transport systems, hospital and outpatient locations (Lawrence \& Kearns, 2005, Nguyen et al., 2011).

\section{Health care initiatives for migrant and refugee communities}

As healthcare providers across the Auckland region have become increasingly aware of the barriers to accessing healthcare for migrant and refugee communities, attention has focused on a range of initiatives to improve access and the health outcomes of these communities (Mortensen, 2011; Auckland City Council, 2013). Such initiatives focus on the creation of bridges between refugee and migrant communities and health service providers, in order to improve perceptions. While acknowledging the many new and ongoing initiatives developed across the wider Auckland region, this article has limited its focus to the public services delivered within the Auckland District Health Board (ADHB) area.

A key initiative has been the establishment of the ADHB Primary Health Interpreting Service. With more than 200 different languages now spoken in the Auckland area, inadequate communication can present a major barrier to accessing care. It is estimated that $29 \%$ of patients presenting for care in the Auckland area require an interpreter (Walker, 2014; ADHB website). The development of the ADHB interpreting service, available free of charge at hospitals, clinics, radiology services and many other primary health services across the region, provides a major resource for both service users and service providers.

The establishment of The Asian Network Inc. (TANI) has been another important initiative (http://www.asiannetwork.org.nz/). TANI is funded by the Ministry of Health to provide health education to Asian (including Chinese, Indian, Korean, Filipino and Afghani) migrant and refugee communities across the Auckland region. TANI provides a range of health education workshops and a quarterly newsletter promoting events and new initiatives within the region's health sector with a focus on CALD communities.

The appointment of a Manager for Asian, Migrant and Refugee Health, a joint position between the ADHB and WDHB (Waitemata District Health Board), responsible for coordinating strategy and delivery of services across the two District Health Boards, is an example of an initiative responding to the specific needs of CALD communities.

The introduction of workers from specific ethnicities and languages, CSWs, to support CALD patients and their families is another strategy within both the DHBs and the NGO sector to improve access and engagement with healthcare services. The CSW role, which acts as a bridge between the provider and the community, is now seen in a variety of healthcare settings throughout the region, both in the community and in the hospital environment (Mortensen et al., 2014).

An important initiative aimed at increasing cultural understanding and knowledge in the health workforce has been the development of the eCALD online training courses (www.caldresources.co.nz). This training platform has provided an effective strategy for addressing cultural understanding and the gaps that can occur between patients 
and health professionals. For example, gaps may include: communication issues, including disclosure and consent; decisionmaking, such as how or when the patient or family should be involved; concepts and understanding of disease; the meaning of pain and other symptoms; attitudes to medication (especially opioid drugs and sedatives) and nutrition; and privacy issues (Koenig \& Gates-Williams, 1995; Lickiss, 2003).

\section{Cultural competence in health care}

In addition to the new initiatives described earlier there has been a renewed emphasis on the importance of cultural sensitivity and awareness in healthcare settings. The need for all health practitioners in Aotearoa New Zealand to be culturally competent was mandated in 2003 with The Health Practitioners Competency Assurance Act (HPCAA). The HPCAA sets standards of clinical competence, cultural competence and requires that all professional bodies set standards for cultural competence. The act itself does not define what is required to be culturally competent but rather leaves it to individual professional bodies to determine the specific requirements of their members.

The notion of cultural competence in social work grew from an increasing consideration of changes in society due to global mobility. It thus developed within a discourse about multicultural social work practice. Nadan argues that the rapid and complex diversity in Western societies saw a "a shift in social work from reliance on the 'melting pot' and assimilation models of the 1960s towards the models of multiculturalism developed in the 1980s" (Nadan, 2014, p. 75).

While there are many different definitions of the term cultural competence, it is commonly used to refer to the ability to work competently with cultures different from our own. A useful enduring definition was provided by The National Association of Social Workers (NASW), in the USA, in 2001:
Cross-cultural competence refers to the process by which individuals and systems respond respectfully and effectively to people of all cultures, languages, classes, races, ethnic backgrounds, religions, and other diversity factors in a manner that recognizes, affirms, and values the worth of individuals, families and communities and protects and preserves the dignity of each. (NASW, 2001, p. 11)

Although cultural competence is an established part of the education curriculum for all health practitioners in Aotearoa New Zealand, it was initially focused on working with Māori, with attention directed towards gaining understanding and awareness of Tikanga Māori, and to developing the appropriate knowledge and skills to work with Māori and their whānau (Ruwhui, 2001).

For healthcare practitioners, including social workers, in Aotearoa New Zealand, an understanding of the impact of culture on healthcare outcomes is due, in large part, to the work done by nursing educator Irihapeti Ramsden and her colleagues in introducing and developing the notion of cultural safety (Papps \& Ramsden, 1996; Ramsden, 1990, 2000). The term kawa whakaruruhau (cultural safety) was used by Ramsden (1990), who drew attention to the poor health outcomes for Māori (Wepa, 2015). Ramsden (1990) argued that Aotearoa New Zealand's healthcare system, constructed by Pākehā and dominated by Western views of health and well-being, was unsafe for Māori: detrimental not only to their tinana (physical) well-being but also to their hinegaro (emotional) and wairua (spiritual) well-being.

While cultural safety and cultural competence are different concepts, they both relate to the delivery of culturally sensitive and appropriate care.

Cultural safety is about the client feeling comfortable or safe with healthcare, while 
cultural competency is about the ability of health practitioners to demonstrate what is needed to achieve that (Vernon \& Papps, 2015, p. 60). The concept of cultural safety has laid the foundation for our current commitment to developing healthcare policies and delivering services that are culturally competent, and safe, for all in our community.

\section{Cultural competence and the role of social work professional bodies in Aotearoa New Zealand}

The social work profession in Aotearoa New Zealand has also shown leadership among the human services recognising early the need for practitioners to be competent to work across cultures (Walker \& Eketone, 2013). It has demonstrated a strong commitment to biculturalism and promoting bi-cultural practice. This commitment based on recognising the rights of Māori as the indigenous people of Aotearoa and is a commitment to the principles and intent of the Treaty of Waitangi (Wilson \& Haretuku, 2015).

The Aotearoa New Zealand Association of Social Work (ANZASW) and the Social Workers Registration Board (SWRB) both have policies that relate to working with Māori and working with different cultural and ethnic groups (ANZASW, 2014, 2019; SWRB, $2011 \mathrm{a}$ b). These policies contain specific behaviours which must be achieved in order for practitioners to be considered competent to practise.

While the ANZASW Practice Standards and the SWRB Core Competencies both pay significant attention to tangata whenua perspectives, they also express a clear commitment by the social work profession to work with our marginalised communities. The ANZASW Code of Ethics (2019) articulates social work's values and commitment to foster belonging and inclusion, promote diversity and connectedness and to challenge exploitation and racism (ANZASW, 2019).
While the Code of Ethics provides a clear mandate for the role of social work in our CALD communities, an increased commitment and ongoing development of the social work curriculum and professional competency requirements will be required if this goal is to be met effectively. This will create an opportunity for the profession to consider how we uphold our commitment to a bicultural model of practice, acknowledging the place of tangata whenua, while we also direct our focus on acquiring the skills and knowledge required for us to practise effectively with the new communities that have made Aotearoa New Zealand their home (Walker \& Eketone, 2013).

\section{Social work education}

The social work profession's commitment to biculturalism is embedded in the current social work education curriculum (Beddoe, 2018) and is also reflected in the SWRB Core Competence Practice Standards, forming an integral part of the process for competency to practise (SWRB, n.d.).

Although Māori make up only $15.4 \%$ of the population, the high number of Māori who require health and social services has meant social workers require a basic knowledge of Māori cultural constructs (tikanga) and a sound knowledge of the Treaty of Waitangi and its principles of Partnership, Participation and Protection (Walker \& Eketone, 2013).

However, the changing demography in Aotearoa New Zealand, particularly in our largest cities, requires practitioners to broaden their cross-cultural knowledge and skills in order to work effectively with an increasingly diverse range of ethnic and cultural groups. There is concern that practitioners are not well enough equipped for these new challenges (Nash \& Trlin, 2004; Park \& Anglem, 2016; Wang 2000).

This observation is echoed in a 2004 study of the experiences of social work practitioners with refugee and migrant communities 
(Nash \& Trlin, 2004). The study drew attention to the gaps in social work education with survey respondents indicating they would like the social work curriculum to include clearer guidelines around cultural competence; they also reported a need for more training, including increased cultural self-awareness and an emphasis on crosscultural communication (Nash \& Trlin, 2004).

It has been proposed that Aotearoa New Zealand should follow the lead of countries such as Finland, establishing (re) settlement work with immigrants, refugees and asylum seekers as a new specialised area of practice for social work; based on a specific body of knowledge with specific training in this area (Nash \& Trlin, 2004).

Social work is also increasingly aligning itself to an approach that focusses on the social determinants of health (Craig, Bejan, \& Muskat, 2013 Pockett, 2014; Pockett \& Beddoe, 2015). Pockett (2014) argues for an understanding and awareness of the social determinants of health in all fields of practice within social work, noting that "socially constructed health inequalities and disparities" are associated with the impact of globalisation and impacts on disadvantaged and oppressed populations (p. 736). Pockett asks for greater awareness of health in social work education, including field placement. It is quite likely that the siloing of curriculum content separates health content from the exploration of refugee, asylum seeker and migrant population concerns.

Fish and Karban (2014) reviewed the inclusion of theorised approaches to health inequalities in social work curricula in the UK and Australia and found scarce evidence of routine inclusion. There appears to be a lack of local evidence relating to this, so future exploration would both enhance and add to our existing understanding in this area.

\section{Cultural support workers}

In North America and Canada, the CSW role, or the role of patient navigators as
CSWs are often known, was developed as a strategy to address the disparities in health outcomes evident in different population groups. The first patient navigator programme, established in the early 1990s in Harlem, New York, was a joint initiative between Dr Harold Freeman and the American Cancer Society (ACS) (Dohan \& Schrag, 2005). The programme was developed in response to concerns over the poor cancer treatment outcomes for Latino and Black American patients.

The term patient navigator was used to describe workers who were enlisted to assist patients: to navigate the often-complex multidisciplinary therapeutic processes involved in healthcare services. The term navigator is descriptive of the role, but the workers are also referred to as community support workers, lay workers, cultural support workers, cultural liaison workers and, in Latino communities, guias (guides) (Sauaia, 2014).

The role of the navigator, or CSW, is to work primarily with underserved populations to identify and address the barriers to achieving better outcomes. They provide the vital link between healthcare providers and service users, bringing valuable cultural knowledge and insights to the multidisciplinary health team, and an understanding of the needs of their particular community.

CSWs can contribute to the health experience in a variety of ways, including being able to "build trust with the community they serve to provide oneon-one, culturally appropriate, patient empowering interventions" (Fischer, Sauaia, \& Kutner, 2007, p. 1024).

An important part of the CSW role is in the developing and building of trust between communities and healthcare providers. For many refugees, the traumatic or unpleasant experiences of authority through the healthcare systems in their countries of origin may have made them 
suspicious and wary of engagement with healthcare services (Lawrence \& Kearns, 2005). The presence of a CSW can contribute to the building of trust, essential for the establishment of an effective, therapeutic relationship.

CSWs or community health workers (another term sometimes used for community supporters of this kind) have been described in the following way:

A Community Health Worker, (CHW) is a frontline public health worker who is a trusted member of and/or has an unusually close understanding of the community served. This trusting relationship enables the $\mathrm{CHW}$ to serve as a liaison/link/intermediary between health/social services and the community to facilitate access to services and improve the quality and cultural competence of service delivery. A CHW also builds individual and community capacity by increasing health knowledge and self-sufficiency through a range of activities such as outreach, community education, informal counselling, social support, and advocacy. (Alvillar, Quinlan, Rush, \& Dudley, 2011, p. 747)

In Aotearoa New Zealand, the activities of a CSW or patient navigator vary depending on the practice setting. The CSW is often required to undertake a broad range of tasks, including: the provision of information about programmes and services; advocacy with healthcare and social service providers; and general emotional and social support to patients and families, which may include accompanying them to doctors' or hospital appointments, transport and interpreting services (Henderson \& Kendall, 2011).

While many CSWs in Aotearoa New Zealand have backgrounds in healthcare, this is not always the case. Currently, with no formal qualifications required and no specific training programme, there is uncertainty about the current process of recruitment and the systems for supporting and training these workers. The lack of specific training and development opportunities for CSWs has also been reflected in the findings from overseas literature. Rosenthal, Wiggins, Ingram, Mayfield-Johnson, and De Zapien's (2011) most recent study into CHW training programmes in the USA echoed the findings of Rosenthal's et al.'s 1998 study, in finding that the most common training provided was stated as "on the job" (2011, p. 256).

The broad range of tasks required of CSWs, and the commitment of CSWs to their communities, can place huge demands on these workers as they struggle to meet the expectations of managers and of the members of their own communities (Henderson \& Kendall, 2011).

\section{CSWs and social work}

While there is recognition of the unique cultural elements of the CSW role, the specific language skills, cultural knowledge and understanding of the particular community, there is also concern about the possible misuse of CSWs by health care providers. With the lack of a clear role definition and boundaries there is potential for misunderstandings and unrealistic expectations leading to an undervaluing of the role and inappropriate use (Nemcek \& Sabatier, 2003).

With the similarity between social work and CSW roles and many tasks common to both roles, including advocacy, provision of information, linking with services and emotional support, there is the potential for CSWs to be required to perform tasks beyond their role and to be seen as a costeffective alternative, or as "surrogate" social workers (Alvillar et al., 2011; Darnell, 2007).

The need for increased understanding into the CSW role and its contribution to health outcomes is recognised by many as being a major challenge for the role (Darnell, 2007; Dohan \& Scrag, 2005; Rosenthal et al., 2011). This theme was echoed in a study which 
explored the role of the unregulated Pasifika workforce here in Aotearoa New Zealand (Perese et al., 2009). This study follows the history and development of the role, training and developmental pathways and key challenges for the development of this workforce. It describes the many challenges for the further development of this role including ambiguous measures, different sets of evaluation priorities, unclear job descriptions and, also importantly, the lack of information currently available on these workers (Perese et al., 2009).

\section{Discussion}

The introduction of CSWs into the healthcare setting as a strategy to improve access to services and improve health and wellbeing outcomes is congruent with the commitment of the social work profession to equality and anti-discriminatory practice. This commitment is articulated in the International Federation of Social Workers' (IFSW) definition, which refers to "principles of social justice, human rights, collective responsibility and respect for diversities" (IFSW, 2014.

However, the establishment of the CSW role does present health social work with some important challenges. One of these is for the profession is to consider whether there has been a sufficient focus on the health needs of refugee and migrant communities; and to examine whether the CSW roles have been developed in response to needs not addressed by current social work practice.

This second challenge also provides a valuable opportunity for practitioners to reflect on their levels of competence and confidence to work with the complex needs of our refugee and migrant communities. How much do they know about the needs of different communities and about the barriers to access and the inequalities that exist for CALD communities in healthcare? And do practitioners possess the skills and knowledge required to be effective in their practice with these communities?
Exploring these questions will require both practitioners and social work educators to actively engage with migrant and refugee communities to learn more about their needs and aspirations and the practice collaborations that would best meet their needs. Research is necessary to ensure that service-users in migrant and refugee communities are active voices in what matters most to them. Research carried out by Maidment, Egan, and Wexler (2016, p. 8) for example, found that, for older adults and their carers in CALD communities, "the demonstration of respect, empathy, genuine interest and giving time were in some cases more important in the interaction, than knowing the details of the particular cultural background, although this too was very helpful." There is a need to identify the areas where more education and training for practitioners is required and how educators can work to develop specific programmes to increase the understanding and knowledge of refugee and migrant communities.

This challenge also presents an exciting opportunity for health social work to broaden its scope in the healthcare setting, and as noted earlier, to take a public health focus, highlighting barriers that exist for many in accessing services and the disparities in healthcare outcomes. This focus is congruent with the social work profession's commitment to equity and anti-discriminatory practice and builds on the profession's important role in promoting diversity and inclusion (IFSW, 2014).

An increased focus on public health focus provides opportunity for collaboration with CSWs to establish and develop programmes that address these barriers and inequalities (Giles, 2009; Pockett, 2014). These collaborative initiatives, uniting the specific skills of social workers with the cultural knowledge and understanding with CSWs would deliver better health outcomes for CALD communities while simultaneously increasing and enhancing social work practitioners' cultural understanding and 
knowledge (Maidment et al., 2016). Spencer et al. (2010) also argue that CSWs are "natural allies for social workers, who share the common goals of social justice and They describe how social work practice can be enhanced by collaborating with CSWs to engage more effectively with marginalised or hard-to-reach communities.

There is also an important part for social work to play in strengthening and supporting the CSW role. Social work practitioners can voice their support for better cultural understanding in healthcare delivery and by advocating for more research to better understand the needs of the CSW workforce and their contribution to the health and wellbeing of communities.

Better understanding gained through research will highlight the unique and distinct features and attributes of CSWs and their role in the healthcare setting. A clearer definition of the CSW role will increase recognition and improve access to appropriate training and professional development opportunities, regular supervision and support, and for them to be accepted as integral, valued members of the multidisciplinary healthcare team.

\section{Conclusion}

The vast demographic changes that have occurred in New Zealand since the 1990s have had a huge impact on the delivery of healthcare services. The introduction of CSWs into the healthcare setting has been an effective strategy for healthcare providers to engage more effectively with our CALD communities.

For health social work, the advent of CSWs in the healthcare setting presents both a challenge and an opportunity. The challenge is for practitioners to reflect on their own levels of competence and confidence in working with the complex needs of our refugee and migrant communities, to identify areas where more training is required and then to seek out learning opportunities that increase their skills and understanding of the many different communities that now call Aotearoa New Zealand home.

It also presents the opportunity for health social work to take more of a public health focus to identify and address disparities in healthcare outcomes. The opportunity for practitioners to engage collaboratively with CSWs in healthcare settings has the potential to both deliver more effective social work practice and strengthen the CSW role thereby ensuring CSWs continue to be a strong voice for the communities they serve.

If health social work is to continue to be a vital and integral part of the health landscape, it must constantly evolve and seek out new areas of practice. Health social work has demonstrated, over time, its ability to adapt to changes in the healthcare environment and now again is presented with a challenge, and the opportunity for the profession to refocus and redefine its role in the healthcare setting.

\section{References}

Alvillar, M., Quinlan, J., Rush, C., \& Dudley, D. (2011) Recommendations for developing and sustaining community health workers. Journal of Health Care for the Poor and Underserved, 22(3), 745-750. doi:https://doi.org/10.1353/hpu.2011.0073

Aotearoa New Zealand Association of Social Workers (ANZASW). (2014). ANZASW Social work practice standards: Enhancing competent social work practice. Retrieved from https://anzasw.nz/wp-content/uploads/ Practice-Standard-Publication-Full-Nov-14.pdf

Aotearoa New Zealand Association of Social Workers (ANZASW). (2019). ANZASW code of ethics. Retrieved from https://anzasw.nz/wp-content/uploads/ANZASWCode-of-Ethics-Final-1-Aug-2019.pdf

Auckland City Council. (2013). Ethnicity and migration in Auckland. Technical Report 2013/012. http://knowledgeauckland.org.nz/assets/publications/ TR2013-012-Ethnicity-and-migration-in-Auckland.pdf

Beddoe, L. (2018). Social work education in Aotearoa New Zealand: Building a profession. Practice, 30(4), 305-320. doi:10.1080/09503153.2018.1478955

Beddoe, L., \& Deeney, C. (2012). Discovering health social work in New Zealand in its published work: Implications for the profession. Aotearoa New Zealand Social Work, 24(1), 41-55.

Chen, M. (2015). Superdiversity stocktake: Implications for business, government and New Zealand. Superdiversity Centre for Law, Policy and Business: Wellington, New Zealand. 
Craig, S. L., \& Muskat, B. (2013). Bouncers, brokers, and glue: The self-described roles of social workers in urban hospitals. Health \& Social Work 38(1), 7-16. doi:10.1093/hsw/hls064

Craig, S. L., Bejan, R., \& Muskat, B. (2013). Making the invisible visible: Are health social workers addressing the social determinants of health? Social Work in Health Care, 52(4), 311-331. doi:10.1080/00981389.2013.764379

Crawley, L.M., Marshall, P.A., Lo, B., \& Koenig, B.A. (2002) Strategies for culturally effective end-of-life care (for the End-of-Life Care Consensus Panel). Annals of Internal Medicine, 136(9), 673-679. doi: https://doi.org/10.7326/0003-4819-136-9200205070-00010

Darnell, J. S. (2007). Patient navigation: A call to action. Social Work, 52(1), 81-84. doi:10.1093/sw/52.1.81

Dohan, D., \& Schrag, D. (2005). Using navigators to improve care of underserved patients: Current practices and approaches. Cancer, 104(4), 848-855. doi:10.1002/cncr.21214

Fischer, S. M., Sauaia, A., \& Kutner, J. S. (2007). Patient navigation: A culturally competent strategy to address disparities in palliative care. Journal of Palliative Medicine, 10(5), 1023-1028. doi:10.1089/jpm.2007.0070

Fish, J., \& Karban, K. (2014). Health inequalities at the heart of the social work curriculum. Social Work Education, 33(1), 15-30. doi:10.1080/02615479.2012.742502

Giles, R., Gould, S., Hart, C., \& Swancott, J. (2007). Clinical priorities: Strengthening social work practice in health. Australian Social Work, 60(2), 147-165.

Goh, M. (2018). Exploring the role of cultural support workers in the New Zealand healthcare setting. Aotearoa New Zealand Social Work, 30(2), 68-74. doi:http://dx.doi.org/10.11157/anzswj-vol30iss2id453

Henderson, S., \& Kendall, E. (2011). "Community navigators": Making a difference by promoting health in culturally and linguistically diverse (CALD) communities in Logan, Queensland. Australian Journal of Primary Health, 17(4), 347-354. doi:10.1071/PY11053

Immigration New Zealand. (2019). From INZ Refugee and Protection Unit Statistics Pack - October 2019. Retrieved from https://www.immigration.govt.nz/documents/ statistics/statistics-refugee-and-protection.pdf

International Federation of Social Workers (IFSW). (2014). Global definition of the social work profession. Retrieved from http://ifsw.org/policies/definition-of-social-work/

Kagawa-Singer, M., \& Backhall, L. (2001). Negotiating crosscultural issues at end of life. Journal of American Medical Association, 286(23), 2993-3001.

Koenig, B. A., \& Gates-Williams, J. (1995). Understanding cultural difference in caring for dying patients. In Caring for patients at the end of life [Special issue]. Western Journal of Medicine, 163, 244-249.

Lawrence, J., \& Kearns, R. (2005). Exploring the "fit" between people and providers: Refugee health needs and health care services in Mt Roskill, Auckland, New Zealand. Health \& Social Care in the Community, 13(5), 451-461. doi:10.1111/j.1365-2524.2005.00572.x

Lickiss, J. N. (2003). Approaching death in multicultural Australia. Medical Journal Australia, 179, S14-S16. PMID: 12964928 Version: 1.
Maidment, J., Egan, R., \& Wexler, J. (2011). Social work with older people from culturally and linguistically diverse backgrounds: Using research to inform practice. Aotearoa New Zealand Social Work, 23(3), 3-15. doi:10.11157/anzswj-vol23iss3id156

Mortensen, A. (2011). Public health system responsiveness to refugee groups in New Zealand: Activation from the bottom up. Social Policy Journal of New Zealand, 37, 123-134.

Mortensen, A., Latimer, S., \& Yusuf, I. (2014). Cultural case workers in child disability services: An evidence-based model of cultural responsiveness for refugee families. Kotuitui: New Zealand Journal of Social Services Online. http://dx.doi.org/10.1080/1177083X.2014.911752

Nadan, Y. (2014). Rethinking "cultural competence" in international social work. International Social Work, 60(1), 74-83. https://doi.org/10.1177/0020872814539986

Nash, M., \& Trlin, A. D. (2004). Social work with immigrants, refugees and asylum seekers in New Zealand: New Settlers Programme. Palmerston North New Zealand: Massey University.

National Association of Social Workers. (2001). NASW standards for cultural competence in social work practice. Washington, DC: Author.

Nemcek, M., \& Sabatier, R. (2003). State of evaluation: Community health workers. Public Health Nursing, 20(4), 260-270.

Nguyen, D. D., Ho, K. H., \& Williams, J. H. (2011). Social determinants and health service use among racial and ethnic minorities: Findings from a community sample. Social Work in Health Care, 50(5), 390-405.

Papps, E., \& Ramsden, I. (1996). Cultural safety in nursing: The New Zealand experience. International Journal for Quality in Health Care, 8(5), 491-497.

Park, H.-J., \& Anglem, J. (2012). The "transnationality" of Koreans, Korean families and Korean communities in Aotearoa New Zealand: Implications for social work practice. Aotearoa New Zealand Social Work, 24(1), 31-40. doi:10.11157/anzswj-vol24iss1id139

Perese, L., Ulugia-Veukiso, A., Samu, K. S., Sepuloni, C., \& Peteru, C. (2009). Workforce development: A study of Pacific non-regulated workers. Report prepared for the Health Research Council Partnership Programme. Auckland, NZ: University of Auckland.

Pockett, R. (2014). "Health in all placements" as a curriculum strategy in social work education. Social Work Education, 33(6), 731-743. doi:10.1080/02615479.2013.874411

Pockett, R., \& Beddoe, L. (2015). Social work in health care: An international perspective. International Social Work, 60(1), 126-139. doi:10.1177/0020872814562479

Ramsden, I. (1990). Kawa whakaruruhau: Cultural safety in nursing education in New Zealand. Wellington, NZ: Ministry of Education.

Ramsden, I. (2000). Cultural safety/Kawa whakaruruhau ten years on: A personal overview. Nursing Praxis in New Zealand, 15(1), 4-12.

Rosenthal, E. L., Wiggins, N., Brownstein, J. N., Johnson, S., Borbón, I. A., \& De Zapien, J. G. (1998). Final report of the National Community Health Advisor Study. Baltimore, MD: Annie E. Casey Foundation. 
Rosenthal, E., Wiggins, N., Ingram, M., Mayfield-Johnson, S., \& De Zapien, J. (2011). Community health workers then and now: An overview of national studies aimed at defining the field. The Journal of Ambulatory Care Management, 34(3), 247-259.

Ruwhiu, L. (2001). Bicultural issues in Aotearoa New Zealand social work. In M. Connolly (Ed.), New Zealand social work - Contexts and practice (pp. 54-71). Auckland, NZ: Oxford University Press.

Sauaia, A. (2014). Quest for health equity. New York, NY: Nova Publishers.

Schofield, V. (2001). Health social work. In M. Connolly (Ed.), New Zealand social work: Contexts and practice (pp. 146-156). Auckland, New Zealand: Oxford University Press.

Social Workers Registration Board. (2011a). SWRB competence to practise social work with different ethnic and cultural groups in New Zealand. Retrieved from http://swrb.govt.nz/policy

Social Workers Registration Board. (2011b). SWRB competence to practise social work with Māori. Retrieved from http://swrb.govt.nz/policy

Social Workers Registration Board. (n.d.). Core competence standards: The SWRB ten core competence standards. Wellington, NZ. Retrieved from https://swrb.govt.nz/forsocial-workers/core-competence-standards/

Spencer, M., Gunter, K., \& Palisano, G. (2010). Community health workers and their value to social work. Social Work, 55(2), 169-180.

Vernon, R., \& Papps, E. (2015). Cultural safety and continuing competence. In D. Wepa (Ed.), Cultural safety in Aotearoa New Zealand (2nd ed., pp. 51-64). Melbourne, VIC: Cambridge University Press.

Walker, R. (2014). Auckland Region DHBs Asian \& MELAA (Middle Eastern, Latin American and African) 2013 census demographic and health profile. Auckland, NZ: Auckland Region District Health Boards.

Walker, S., \& Eketone, A. (2013). Biculturalism as an approach to social work. In H. K. Ling, J. Martin, \& R. Ow (Eds.), Cross-cultural social work: Local and global (pp. 67-86). South Yarra, VIC: Palgrave Macmillan.

Wang, J. (2000). Highlighting the gaps in existing New Zealand social services: Settlement programmes and Asian services. Unpublished paper presented at the Aotearoa New Zealand Association of Social Workers (Inc) Biennial Conference, Auckland, New Zealand.

Weld, N. (2009). Resuscitating health social work. Aotearoa New Zealand Social Work Review, 21/22(4), 25-33.

Wepa, D. (Ed.). (2015). Cultural safety in Aotearoa New Zealand (2nd ed.). Melbourne, VIC: Cambridge University Press.

Wilson, D., \& Haretuku, R. (2015). Te Tiriti o Waitangi/Treaty of Waitangi 1840. In D. Wepa (Ed.), Cultural safety in Aotearoa New Zealand (2nd ed., pp. 79-93). Melbourne, VIC: Cambridge University Press. 